\title{
IOGURTE DE LEITE DE BÚFALA SABORIZADO COM MANGA (Mangifera indica L.): ACEITAÇÃO SENSORIAL E CUSTO DE PRODUÇÃO
}

\author{
Lilaine de Sousa Neres ${ }^{1}$; José de Brito Lourenço Júnior ${ }^{1}$; Evelyn Azevedo Pacheco; \\ Ranna Catarine da Rocha Monteiro ${ }^{1}$; Suenne Taynah Abe Sato ${ }^{2}$; Suely Cristina Gomes \\ de Lima ${ }^{3}$; Alexandre Rossetto Garcia ${ }^{4}$; Benjamim de Souza Nahúm.

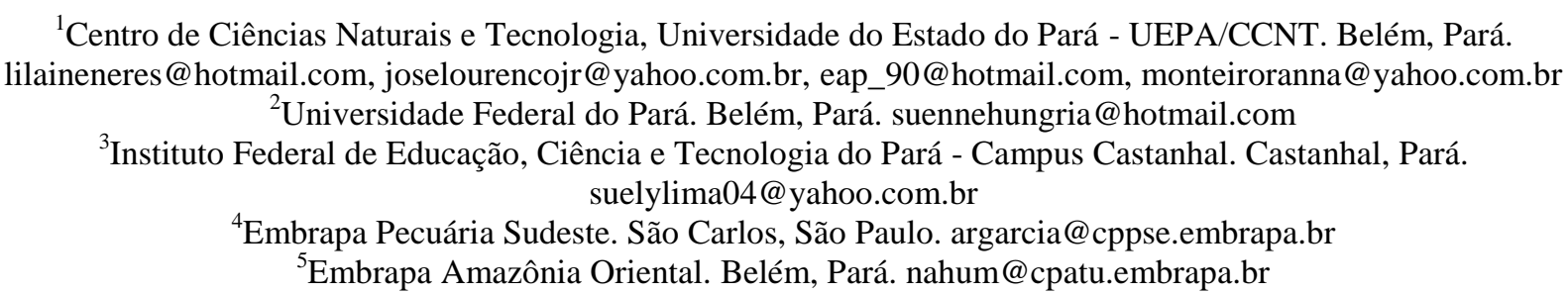

RESUMO: Objetivou-se elaborar e avaliar iogurte de leite de búfala saborizado com manga (Mangifera indica L.), fruta tropical amplamente consumida na região Norte. O leite de búfala (Bubalus bubalis) foi submetido ao tratamento térmico $\left(95^{\circ} \mathrm{C} / 5\right.$ minutos), resfriado a $45{ }^{\circ} \mathrm{C} \mathrm{e}$ inoculado com 2,5\% de cultura láctica, seguido da adição de calda preparada com $35 \%$ de polpa de manga, 35\% de sacarose e 30\% de água, homogeneizados por cinco minutos. No dia seguinte à elaboração, o derivado foi submetido à avaliação sensorial, com provadores não treinados. A análise da avaliação sensorial apresentou boa aceitabilidade, com nota média de 7,4. Quanto à intenção de compra, 47,3\% dos provadores, com certeza, comprariam o produto, 26,4\%, talvez comprariam, e 26,3\% não comprariam. A análise econômica indicou reduzido custo de produção do derivado, cerca de $\mathrm{R} \$ 0,20$ (vinte centavos de real), para cada $100 \mathrm{ml}$. O iogurte de leite de búfala constitui-se excelente derivado e pode ser usado como alternativa em Programas Especiais, financiados pelo Governo, com vista à redução da fome de comunidades de baixa renda, pois possui elevado valor calórico/proteico, baixo custo, utiliza matérias primas regionais, além da geração de renda e trabalho, através do incentivo à produção leiteira e à fruticultura regionais.

PALAVRAS-CHAVE: Amazônia Oriental, derivado lácteo, fruticultura regional.

\section{YOGURT BUFFALO MILK FLAVORED WITH MANGO (Mangifera indica L.): SENSORY ACCEPTION AND PRODUCTION COST}

\begin{abstract}
The objective was to develop and evaluate buffalo milk yogurt flavored with mango (Mangifera indica L.), tropical fruit widely consumed in the North Region, Brazil. Buffalo milk (Bubalus bubalis) was subjected to heat treatment $\left(95^{\circ} \mathrm{C} / 5\right.$ minutes), cooled to $45{ }^{\circ} \mathrm{C}$ and inoculated with $2.5 \%$ lactic culture, followed by addition of sweet sauce prepared at $35 \%$ mango pulp, 35\% sucrose and $30 \%$ water, homogenized for five minutes. The day after the elaboration, the derivative was subjected to sensory evaluation, with untrained. The analysis showed good acceptance, with an average score of 7.4. As for intent to purchase $47.3 \%$ of the judges, of course buy the product, $26.4 \%$, may buy, and $26.3 \%$ would not buy. The economic analysis indicated reduced cost of production, about US\$ 0.20 (twenty cents) per $100 \mathrm{ml}$. Yogurt buffalo milk is excellent and can be used as an alternative for Special Programs, funded by the Government, with a view to reducing hunger in low-income communities, because it has high fat/protein, low-cost and used regional materials, in addition
\end{abstract}


to income generation and employment through the stimulation of milk production and fruit growing region.

KEY-WORDS: dairy products, Eastern Amazon, fruit regional.

Uma importante função dos bubalinos na pecuária é a produção de leite e neste segmento destacam-se os países asiáticos e a Itália. No Brasil, o leite de búfala e seus derivados têm sido de grande importância, em pequenas e médias propriedades rurais (MOURA CARVALHO et al., 1997; TEIXEIRA; BASTIANETTO; OLIVEIRA, 2005).

A búfala tem grande potencial como produtora de leite, pelo seu maior valor nutritivo e rendimento industrial, principalmente queijos e iogurtes, quando comparados com o leite bovino, além de maior rusticidade, o que permite a sua criação em regiões alagadas, inadequadas para gado bovino. É importante salientar que o produtor de recebe um valor diferenciado pelo litro de leite in natura de búfala, em torno de 40 a $50 \%$ a mais que o valor pago pelo de vaca bovina (AMARAL; ESCRIVÃO, 2005).

O iogurte é um produto alimentício muito apreciado e consumido, oriundo de processo fermentativo por bactérias específicas, com consequente diminuição do $\mathrm{pH}$, que modifica suas propriedades sensoriais (ORDÓÑEZ-PEREDA et al.,
2005). As bactérias mais utilizadas pela indústria de alimentos são Lactobacillus bulgaricus e Streptococcus thermophilus, embora algumas bifidobactérias e leveduras, também, sejam empregadas (PIMENTEL, 2005).

Em geral, os derivados lácteos disponíveis utilizam sabores de frutas temperadas e a Amazônia oferece frutas com sabores e aromas diferenciados e, dentre elas, a manga (Mangifera indica L.), com grande quantidade de polpa, aroma e cor agradáveis, além da aparência exótica, rica em carotenóides e carboidratos (BRANDÃO et al., 2003).

Dessa forma, o trabalho visou elaborar e avaliar sensorial e economicamente o iogurte de leite de búfala, saborizado com manga, como indicação de inserção na merenda escolar da rede pública do ensino fundamental.

Utilizou-se leite de búfala da Unidade de Pesquisa Animal "Dr. Felisberto Camargo" (01 $26^{\circ} \mathrm{S}$ e $\left.48^{\circ} 24^{\prime} \mathrm{W}\right)$, da Embrapa Amazônia Oriental, Belém, Pará. O leite foi submetido ao tratamento térmico $\left(95{ }^{\circ} \mathrm{C} / 5\right.$ minutos), resfriado a 45 ${ }^{\circ} \mathrm{C}$ e inoculado com $2,5 \%$ de cultura 
láctica. O tempo de fermentação foi calculado, a partir do início da inoculação, até pH igual a 4,6, seguido de resfriamento a $5{ }^{\circ} \mathrm{C}$, e armazenamento em câmara fria, na mesma temperatura.

A manga foi submetida ao branqueamento e cortada em cubos. Para misturá-la ao iogurte, preparou-se calda com $35 \%$ de polpa da fruta, $35 \%$ de sacarose e 30\% de água, passada em liquidificador e submetida à esterilização, para prevenir possível contaminação, até se obter produto viscoso e brilhante. A calda foi resfriada a $10^{\circ} \mathrm{C}$ e homogeneizada com o iogurte natural, em liquidificador, por cinco minutos. $\mathrm{O}$ iogurte foi acondicionado em embalagens de plástico higienizadas e armazenado sob refrigeração.

No dia seguinte, o derivado foi submetido à avaliação sensorial, com 50 provadores não treinados, de ambos os sexos e em bom estado de saúde. As amostras foram servidas em copos descartáveis $(50 \mathrm{~mL})$ a aproximadamente 5 ${ }^{\circ} \mathrm{C}$, além de água mineral, para limpeza do palato. Simultaneamente à análise, foi fornecida ficha com escala hedônica estruturada de nove pontos, que corresponde a "desgostei muitíssimo" (1) à "gostei muitíssimo" (9) e intenção de compra de 3 pontos, "não compraria" (1) até "com certeza compraria" (3).
O cálculo do custo econômico para produção do derivado compreendeu ingredientes adicionados, com valores praticados no mercado varejista local, em Belém, Pará, mão de obra, com base no salário mínimo vigente relacionado a um dia de trabalho, depreciação de equipamentos e outras despesas, relacionadas a junho de 2012.

A análise da avaliação sensorial do iogurte de leite de búfala, saborizado com manga, apresentou boa aceitabilidade, nota média de 7,4, o que é significativo, pois, Dutcosky (2007) afirma que para ser considerado aceitável o alimento precisa apresentar em sua avaliação nota igual ou superior a 70\%. Moraes et al. (2011) mencionam médias entre 6-8, em iogurte elaborado com leite de vaca, enquanto Siqueira et al. (2011), em torno de 8, com o preparado com leite de búfala, saborizados com diferentes concentrações de polpa, respectivamente, de cupuaçu e castanha-do-pará, o que indica seu potencial para consumo.

Quanto à intenção de compra, 47\% dos provadores "com certeza comprariam o produto", $27 \%$ "talvez comprariam" e $26 \%$ "não comprariam", fato que o indica como opção para a agroindústria de laticínios.

De acordo com os cálculos para produzir 120 litros de iogurte de manga, elaborado com leite bubalino, 
considerando-se rendimento de $20 \%$ do derivado, em relação ao produto "in natura" (HUHN et al., 1986), foram gastos $\mathrm{R} \$ 201,40$ (duzentos e um reais e quarenta centavos), o que corresponde à cerca de $\mathrm{R} \$$ 0,17 (dezessete centavos de real), por cada $100 \mathrm{ml}$ do derivado (Tabela 1).

Tabela 1. Custos para elaboração de 120 litros de iogurte de leite de búfala sabor manga.

\begin{tabular}{lcc}
\hline Componente & Valor unitário (R\$) & Valor total (R\$) \\
\hline Mão de obra e encargos & 43,13 & 43,13 \\
Leite (100 litros) & 0,70 & 70,00 \\
Manga "in natura" (6 kg) & 2,00 & 12,00 \\
Açúcar (20 kg) & 2,50 & 50,00 \\
Subtotal 1 & - & 175,13 \\
Equipamento (depreciação 10\%) & - & 17,51 \\
Outros (5\%) & & 8,76 \\
Total & & 201,40 \\
\hline
\end{tabular}

*Cálculos realizados em junho de 2012.

O fornecimento diário de $200 \mathrm{~mL}$ de iogurte de leite de búfala, aproximadamente 321 calorias, é suficiente para o suprimento de $15 \%$ da demanda calórico-proteica prevista pelos Programas de Merenda Escolar (QUEIROZ et al., 2001). Cada aluno suprido com $200 \mathrm{~mL}$ de iogurte de leite de búfala saborizado com manga terá um custo de $\mathrm{R} \$ 0,34$ (trinta e quatro centavos de real), enquanto que iogurtes de leite bovino alcançam custo médio de $\mathrm{R} \$ 0,36$ (trinta e seis centavos de real) por $200 \mathrm{~mL}$ (CARNEIRO \& RODRIGUES, 2010).

Entretanto, considerando-se que a destacada produção na Amazônia Oriental de leite de búfala e de frutas regionais (cupuaçu, bacuri, etc...), que pode ser produzida localmente, o custo de produção tende a ser consideravelmente reduzido, o que viabiliza a elaboração de derivados lácteos, tais como iogurte, de baixo custo e acessível à merenda escolar.

Atualmente, o valor estipulado pelo governo por aluno/dia letivo é definido de acordo com a etapa de ensino, $\mathrm{R} \$ 1,00$ (um real) para creches, $\mathrm{R} \$ 0,50$ (cinquenta centavos de real) para pré-escola, $\mathrm{R} \$ 0,60$ (sessenta centavos de real) para escolas indígenas e quilombolas e, de acordo com a Lei $\mathrm{n}^{\mathrm{o}} 11.947$, de 16/6/2009, 30\% desse valor devem ser investidos na compra 
direta de produtos da agricultura familiar, medida que estimula o desenvolvimento econômico dessas comunidades (FNDE, 2012).

O rebanho brasileiro de bubalinos soma um milhão e duzentas mil cabeças, com a maior parte concentrada na Região Norte (63\%), e o Pará possui 435.937 de excelentes animais produtores, tanto de carne quanto de leite. Com relação à produção de leite há destaque para planteis de produtores dos municípios de Santa Isabel do Pará, Nova Timboteua e Ipixuna, Pará, onde animais produzem cerca de 12

\section{AGRADECIMENTOS}

À Embrapa Amazônia Oriental, CNPq e UEPA, através dos projetos aprovados nos Editais FAPESPA/UEPA 006/201 e 0061/2010, que concederam recursos humanos, materiais e financeiros.

\section{REFERÊNCIAS}

AMARAL， F.R.; ESCRIVÃO, S. C. Aspectos relacionados à búfala leiteira.

\section{Revista Brasileira de Reprodução}

Animal, Belo Horizonte, v.29, n.2, p.111117, abril/jun. 2005.

BRANDÃO, M. C. C.; MAIA, G. A.; LIMA, D. P.; PARENTE, E. J. S.; CAMPELlO, C. C.; NASSU, R. T.; $\mathrm{kg}$ de leite/dia, em uma ordenha diária (IBGE, 2009; BARBOSA, 2005).

Dessa forma, observou-se que o derivado lácteo bubalino obteve ótima aceitação, e constitui alternativa para uso na merenda escolar e suplementação de populações carentes do país, principalmente da Amazônia Oriental, pois atende a demanda calórico-protéica prevista em Programas Governamentais. A obtenção do derivado é plenamente viável, além de permitir o uso de outras frutas regionais, de elevados valores nutricionais, bem como contribuir para geração de renda e incentivo à pequena produção rural.

FEITOSA, T.; SOUSA, P. H. M. Análise físico química, microbiológica e sensorial de frutos de manga submetidos à desidratação osmótico solar. Revista Brasileira de Fruticultura. v. 25, n.1, dez. 2003.

FNDE. Fundo Nacional de Desenvolvimento da Educação. Programas de Alimentação Escolar. 2012. Disponível em:

$<$ http://www.fnde.gov.br/programas/alime ntacao-escolar/alimentacao-escolarapresentacao>. Acesso em 30 de janeiro de 2013.

CARNEIRO, H.; RODRIGUES, P. V. Como transformar excedente do leite em 
boa fonte de renda: produção de doce de iogurte. Panorama do Leite, Juiz de Fora, v.4, n.39, fev. 2010.

DUTCOSKY, S. D. Análise sensorial de alimentos. 2 ed. Curitiba: Champagnat, 2007. 239p.

HÜHN, S.; LOURENÇO JUNIOR, J.B.; MOURA CARVALHO, L.O.D.; NASCIMENTO, C.N.B.; VIEIRA, L.C. Aproveitamento do leite de búfala em produtos derivados. In: SIMPÓSIO DO TRÓPICO ÚMIDO, 1., 1984, Belém. Anais. Belém: EMBRAPA - CPATU, 1986. v.5. p. 265-269 (EMBRAPA CPATU. Documentos, 36).

MORAES, C. G.; LIMA, P. M.; WANDERLEY JUNIOR, M. A.; SOUZA, M. A.; SILVEIRA, S. T. Desenvolvimento e avaliação sensorial de iogurte com polpa de cupuaçu. Higiene alimentar, v.25, n.194/195, p.1.304-1.306. 2011

MOURA CARVALHO, L.O.D.; LOURENÇO JUNIOR, J.B; TEIXEIRA NETO, J.F. Programa de soerguimento da bubalinocultura no Estado do Pará. Belém: Associação Paraense de Criadores de Búfalos, 1997. 8p.

ORDÓÑEZ-PEREDA, J.A.; RODRIGUES, M.I.C.; ALVAREZ, L. F.; SANZ， M.L.G.; MINGUILLÓN,
G.D.G.F.; $\quad$ PERALES, $\quad$ L.H.; CORTECERO, M.D.S. Tecnologia de alimentos. Vol. 2 - Alimentos de origem animal. Trad. Fátima Murad. Porto Alegre: Artmed, 2005.

PIMENTEL, C.V.M.; FRANCKI, V.M.; GOLLÜCKE, A.P.B. Alimentos funcionais: Introdução às principais substâncias bioativas em alimentos. São Paulo: Varela, 2005.

QUEIROZ, L. S. O.; LOURENÇO JÚNIOR, J. B.; VIEIRA, L. C.; SOUZA, C. L.; SANTOS, N. F. A. Características físico-químicas, microbiológicas e aceitabilidade de iogurte de leite de búfala para merenda escolar. 2001. 17p. (Embrapa Amazônia Oriental. Documentos, 109).

SIQUEIRA, L. S.; SOUSA, F. F.; LOURENÇO JÚNIOR, J. B.; NERES, L. S. Iogurte de leite de búfala saborizado com cupuaçu (Theobroma grandiflorum Schum) e enriquecido com torta de castanha-do-pará (Bertholletia excelsa bonpl). Higiene Alimentar, v.25, n.194/195, p.1.314-1.316. 2011

TEIXEIRA，L. V.; BASTIANETTO, E.; OLIVEIRA, D. A. A. Leite de búfala na indústria de produtos lácteos. Revista Brasileira de Reprodução Animal, v.29, n.2, p.96-100, abril/jun. 2005. 